\title{
Soft Chemistry Routes to New Nanosize Materials
}

\author{
Khaled Melghit
}

Chemistry Department, College of Science, Sultan Qaboos University. P.O. Box 36, Postal code 123, Sultanate of Oman. E-mail: melghit@squ.edu.om.

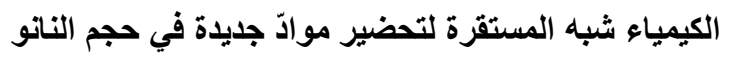

خالا ملفيت

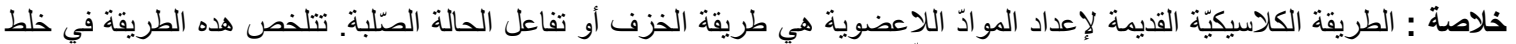

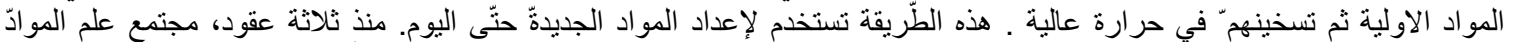

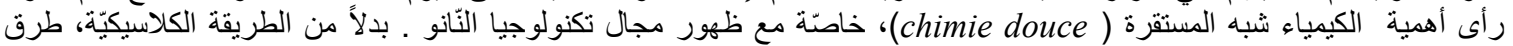

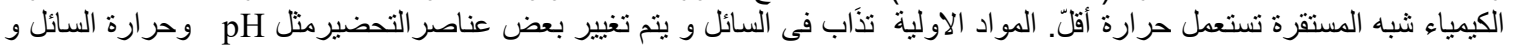

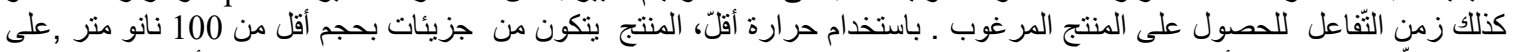

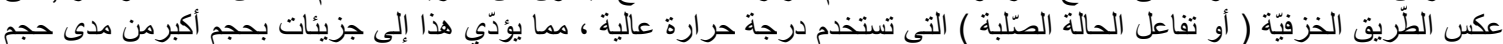

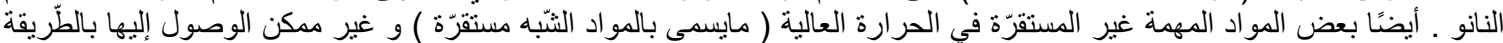

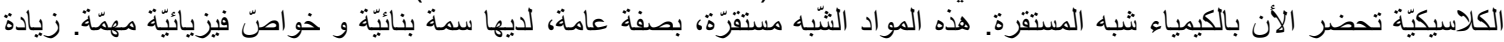

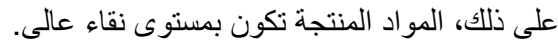

ABSTRACT : The old classical method for preparing inorganic materials is by the ceramic route or solid state reaction. It consists of mixing the starting materials at an elevated temperature. This method has been used for preparing numerous new materials until today. Three decades ago, the materials science community was aware of soft chemistry synthesis or chimie douce, especially with the emergence of nanotechnology field. Instead of the classical method, which involves high temperature, soft chemistry techniques use lower temperatures. In general, starting materials are dissolved in a liquid phase and different parameters such as $\mathrm{pH}$, temperature and reaction time are adjusted in order to obtain the desired product. By using a lower temperature of preparation, the product obtained shows nanosize particles, with sizes lower than 100 nanometers. In contrast, the ceramic route (or solid state reaction) using higher temperatures leads to bigger particles size that are out of the nanosize range. Also, some interesting phases that are not stable at elevated temperatures (named metastable phases) and are not accessible by the classical method, are now prepared by the soft chemistry technique. Usually these metastable phases have interesting structural features and important physical properties. Adding to that, the product is obtained with a higher level of purity.

KEYWORDS : Solid state reaction, soft chemistry, metastable phase, nanosize materials.

\section{Introduction}




\section{KHALED MELGHIT}

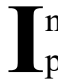
norganic materials (or mineral compounds) are important classes of chemistry. Our development was not possible without these materials. It is recognized that many inorganic materials played a role in the history of human civilization; beginning from stone, copper, bronze, iron, aluminum and recently silicon which is the key to electronic and computer development. With new advanced inorganic materials being discovered, our life becomes easier and more technology is implemented in our daily life. Let's take one example: the development of batteries leads to smaller mobile phones that can fit in our pocket. This has been possible because of new inorganic materials that can deliver high current energy with a smaller mass. The research is still going on to improve these materials in the hope to commercialize, in the future, an electrical car in the same manner as in the present oil-based cars. This goal can be reached if only new materials are discovered with the desired properties. This needed improvement on the techniques of preparation and new techniques should be tried. Classical preparation or ceramic route was known from the old age as a fire preparation. Although, until today, the method still remains proves its capability in preparing many new materials. However, it shows deficiency for preparing nanosize materials or metastable phases that usually show interesting properties and are needed for today's applications. Chimie douce or soft chemistry, that uses lower temperature, often room temperature, was found to be the alternative for ceramic preparation. The present review deals with such a preparation method.

\section{Ceramic route}

The classical method of preparation of inorganic materials is called solid state reaction or ceramic route. It is a very old method; it consists of mixing the starting materials in a container and heating the mixture at elevated temperature. The temperature used is often near to the melting point of the starting materials. In some reactions, one or more starting materials may melt. The reaction is based on the diffusion of atoms between the particles of starting materials to form the new product. This method has been used to prepare many new materials for a very long time, as it is said in the holy Qur'an, chapter 18, verse 96: (Bring me blocks of iron; until when he had filled up the space between the two mountain sides, he said: Blow, until when he had made it (as) fire, he said: Bring me molten brass which I may pour over it). The method used by prophet zul-qarnain (peace be upon him) is indeed a solid state reaction. Until the present time, solid state reaction remains a powerful method and a choice for many researchers for preparing inorganic materials. In a typical solid state reaction the starting materials are mixed and ground in a pestle and mortar or using a ball milling system. Then, the mixture is heated on a crucible at high temperature. Usually different grinding at different stages of heating are needed followed by pelletization in order to increase the contact between starting materials. As the product is formed the constituents have to diffuse through the product phase which may be difficult without several grinding stages. Figure 1 shows a good contact between crystallites of starting materials.

Starting reagents with large surface area are suitable. It is recommended to start with reagents that decompose prior to or during reaction like carbonates or nitrates. It is suitable to use reactants with crystal structures similar to that of the product (topotactic reactions: to enhance the rate of nucleation of the product phase). The diffusion coefficient increases with temperature, rapidly as you approach the melting point. This concept leads to Tamman's Rule: extensive reaction will not occur until the temperature reaches at least $2 / 3$ of the melting point of one or more of the reactants. It is important before starting a solid state reaction to have the knowledge of some parameters such as the Phase diagram of the system under study in order to know the nature of the product that could be obtained at a given temperature. Example of phase diagram is given on Figure 2. At a given temperature, one or more than one phase could exist. To obtain a pure phase it is necessary to have knowledge of such phase diagram. 


\section{SOFT CHEMISTRY ROUTES TO NEW NANOSIZE MATERIALS}

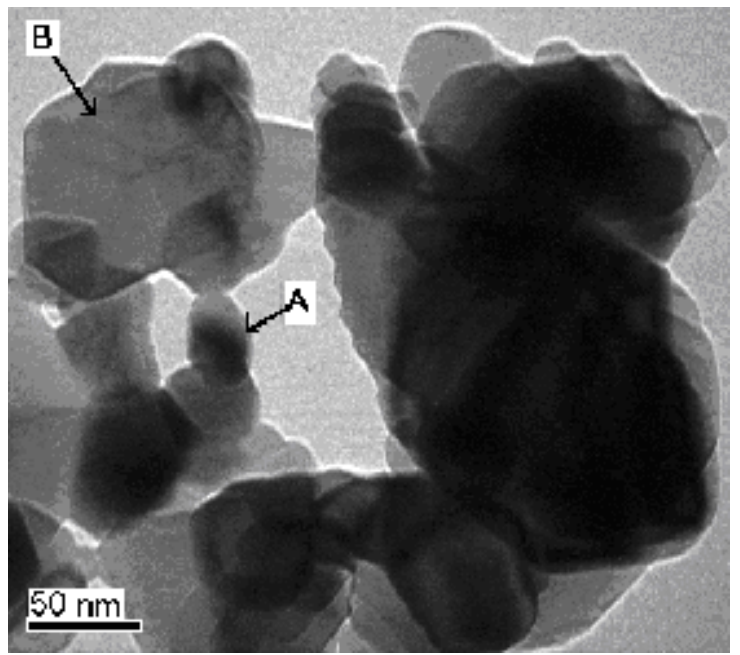

Figure 1. Transmission Electron Micrograph (TEM) showing the contact between the two starting materials (A and $\mathrm{B}$ ) in a solid state reaction.

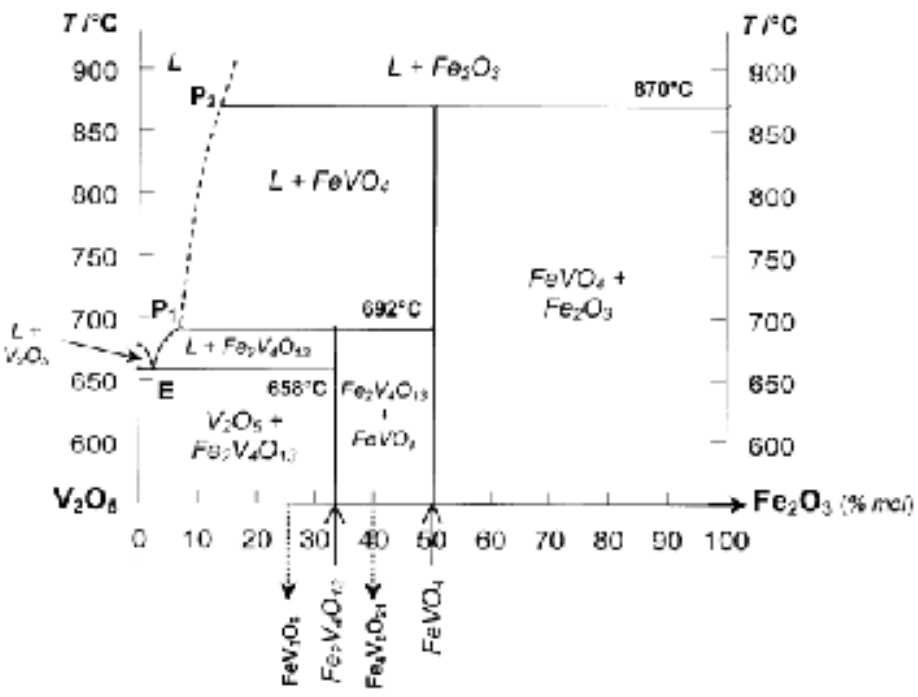

Figure 2. Binary diagram of the $\mathrm{V}_{2} \mathrm{O}_{5}-\mathrm{Fe}_{2} \mathrm{O}_{3}$ system.

\subsection{Examples of solid state reactions}

(a) Preparation of $\mathrm{ZnTiO}_{3}$ (Chang et al, 2004): $\mathrm{ZnTiO}_{3}$ was prepared by conventional solid state reaction using a mixture of $\mathrm{ZnO}$ with $\mathrm{TiO}_{2}$. The starting materials were mixed in ethanol by ball milling for 24 hours and annealed at different temperatures: $700^{\circ} \mathrm{C}, 800^{\circ} \mathrm{C}, 900^{\circ} \mathrm{C}$ and $1000^{\circ} \mathrm{C}$ each for 24 hours. Then the mixtures were pressed into discs and sintered at $800-940^{\circ} \mathrm{C}$ for 24 hours. 


\section{KHALED MELGHIT}

(b) Preparation of $\mathrm{La}_{1-\mathrm{x}} \mathrm{Fe}_{\mathrm{x}} \mathrm{VO}_{4}$ (Varma et al, 2004): For this preparation a mixture of oxides $\mathrm{V}_{2} \mathrm{O}_{5}, \mathrm{La}_{2} \mathrm{O}_{3}$ and $\mathrm{Fe}_{2} \mathrm{O}_{3}$ was used. This mixture was heated at $900^{\circ} \mathrm{C}$ for $8-10$ hours, and then it was pelletized into discs and heated at $600^{\circ} \mathrm{C}$ for 90 hours and at $800^{\circ} \mathrm{C}$ for 24 hours with grinding in between.

(c) Preparation of $\mathrm{Ba}_{1-\mathrm{x}} \mathrm{Ca}_{\mathrm{x}} \mathrm{TiO}_{3}$ (Chen et al, 2004): In this preparation, carbonate of $\mathrm{BaCO}_{3}$ and $\mathrm{CaCO}_{3}$ and $\mathrm{TiO}_{2}$ powder were used. They were mixed by ball milling for 24 hours and then calcined at $1100^{\circ} \mathrm{C}$ in air for 3 hours. The calcined powder added with 8 wt. $\%$ of PVA was pressed into discs and then sintered at $1350-1375^{\circ} \mathrm{C}$ for 3 hours.

(d) Also preparation of ( $\mathrm{Ba}, \mathrm{Sr}$ )-Mn oxides (Heiras et al, 2002): $\mathrm{BaCO}_{3}, \mathrm{SrCO}_{3}$ and $\mathrm{Mn}_{2} \mathrm{O}_{3}$ in appropriate atomic ratios were mixed, ground and calcined at $850^{\circ} \mathrm{C}$ for $24 \mathrm{~h}$ following two steps at 350 and $650^{\circ} \mathrm{C}$ for 3 hours each. The calcined powder was reground and pressed into $1 \mathrm{~cm}$ diameter pellets at a pressure of $650 \mathrm{Kg} / \mathrm{cm}^{2}$. Pellets were sintered at $950^{\circ} \mathrm{C}$ for 24 hours following two pre-sintering steps at 650 and $750^{\circ} \mathrm{C}$ for 3 hours each.

From these examples it is clear that the solid state reaction goes through a mixing and heating steps. Thus, the English description: shake and bake. It is therefore necessary to put as much particles as possible in contact in order for the reaction to go to completion. In general many grinding, pressing and heating are needed. However in reality it is not possible that all starting materials will react completely and a small amount of reactant always exists with the product that could affect its physical properties. Often, the use of high temperature in the method of preparation leads to sublimation of small amount of starting element, for instance oxygen which will affect the oxidation state of the final product. The use of high temperature reaction also does not allow the control of size and morphology of the product particles. High temperature leads to bigger particles with strong agglomeration that reduced the surface area and hence the reactivity of the product in chemical or physical applications. Another inconvenience of the solid state reaction is the lack of preparing new metastable phases. In several systems a metastable phase could exist beside the stable phase (the known phase). The metastable phase has the same chemical composition as the known phase but with different crystalline structure. Metastable phases are stable at relatively lower temperature; above this temperature the phase will transform to give the known stable phase that is usually obtained at higher temperature. Because the solid state reaction uses high temperature in the method of preparation, it is not possible to prepare these phases. Other inconvenience is the cost of preparation since a much higher temperature used requires a higher energy and therefore involves a higher cost. For this raison, about thirty years a go, the scientific community started to think of new methods of preparation whereby lower temperatures could be used. This new method will have the possibilities for preparing new advanced inorganic materials, in general metastable and nanosize phases, to meet the actual technological challenge.

\section{Soft chemistry (Chimie douce)}

Soft chemistry is a technique that uses low temperatures for preparing inorganic materials. Historitically, soft chemistry or chimie douce was introduced by a French scientist three decades ago (J. Livage, 1977). The idea comes from nature: the silicate which is prepared by industries at elevated temperatures (more than $1000^{\circ} \mathrm{C}$ ) is found to be prepared at room temperature by the living organism diatoms and radiolarians in the marine area from the small amount of silica dissolved in the water with sophisticated, artistic and beautiful shapes Figure 3. However, industry with the present development is not able to obtain similar shapes.

It was important to study the mechanism involved for preparing such materials at lower temperatures. In such preparation, it is clear that a solution method or a wet method should be used instead of the dry method used by solid state reaction (J. Livage, 2001). With time the scientific community was aware of the importance of soft chemistry in preparing new advanced inorganic materials which cannot be prepared by solid state techniques. Different progresses were made in the field over the entire world especially in France, Germany, England, Japan and North American. Presently, also many companies are dealing with soft chemistry techniques; their products are obtained at lower temperature especially with the emergence of nanotechnology and composite materials (inorganic-organic and inorganic-bioorganic composites). Two major important benefits 


\section{SOFT CHEMISTRY ROUTES TO NEW NANOSIZE MATERIALS}

of the soft chemistry techniques can be cited here: preparation of new metastable phase and preparation of nanosize materials.

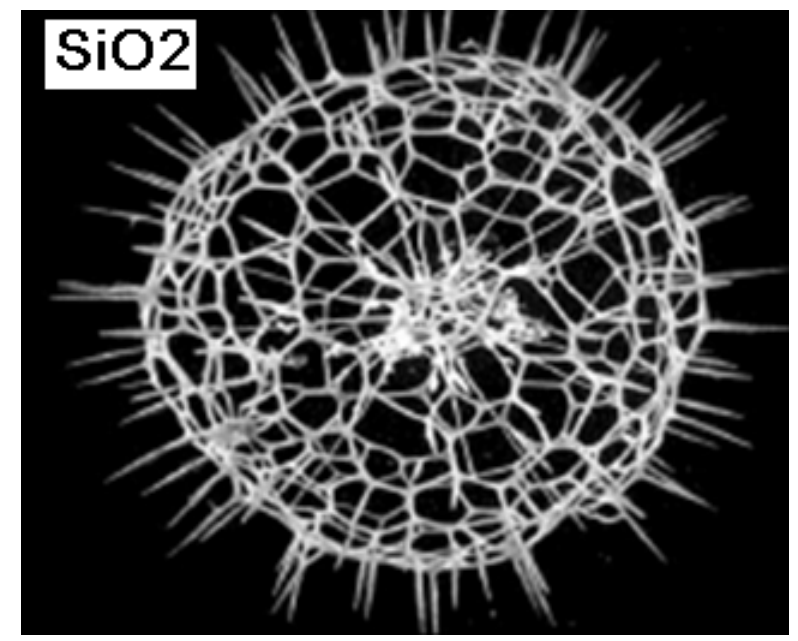

Figure 3. $\mathrm{SiO}_{2}$ formed by a living organism at normal temperature.

\subsection{Preparation of metastable phase}

One of the important advantages of soft chemistry is its capability in preparing new metastable phases which cannot be prepared by the classical techniques using high temperature. Usually metastable phase presents open crystal structure and shows interesting physical and chemical properties. (Poeppelmeier et al., 1994; Rouxel, 1988, Weiss, 1973; Melghit et al, 1999). For example several years ago, a new metastable form of chromium orthovanadate was prepared (Touboul and Melghit, 1995 ); up to that time chromium orthovanadate $\mathrm{CrVO}_{4}$ presents only one form which can be prepared by a solid state reaction at elevated temperature of $1000^{\circ} \mathrm{C}$ from mixed oxide of vanadium and chromium.

$$
1000^{\circ} \mathrm{C}
$$

$$
\mathrm{V}_{2} \mathrm{O}_{5}+\mathrm{Cr}_{2} \mathrm{O}_{3} \rightarrow 2 \mathrm{CrVO}_{4}
$$

The solid state reaction cannot leads to preparation of new form of $\mathrm{CrVO}_{4}$ if they exist because they are only stable at lower temperature $\left(<1000^{\circ} \mathrm{C}\right)$. A soft chemistry technique can be used starting from vanadium oxide dissolved in water and aqueous solution of chromium nitrate.

$\begin{array}{rrrr} & \mathrm{V}_{2} \mathrm{O}_{5} 1.8 \mathrm{H}_{2} \mathrm{O}+ & 2 \mathrm{Cr}\left(\mathrm{NO}_{3}\right)_{3}{ }_{3} \underset{\text { (aq }}{9} \mathrm{O} \rightarrow & \text { Precipitate } \\ \text { (aqueous) } & \text { (aqueous) } & \text { stirring } & \end{array}$

The precipitate obtained was amorphous however it crystallized at $550^{\circ} \mathrm{C}$ to give a new phase. The new phase has a monoclinic crystal system different from the crystal system of the stable phase which is orthorhombic Figure 4. If the new phase is heated at higher temperature it will leads to the stable phase orthorhombic $\mathrm{CrVO}_{4}$. The two phases have the same chemical composition but different crystalline structures Figure 5 . The new metastable phase has shown good catalytic properties especially when it is mixed with other metals (Song et al, 2002; Shishido et al, 2003; Song et al, 2003; Zhaoxia et al, 2001). 


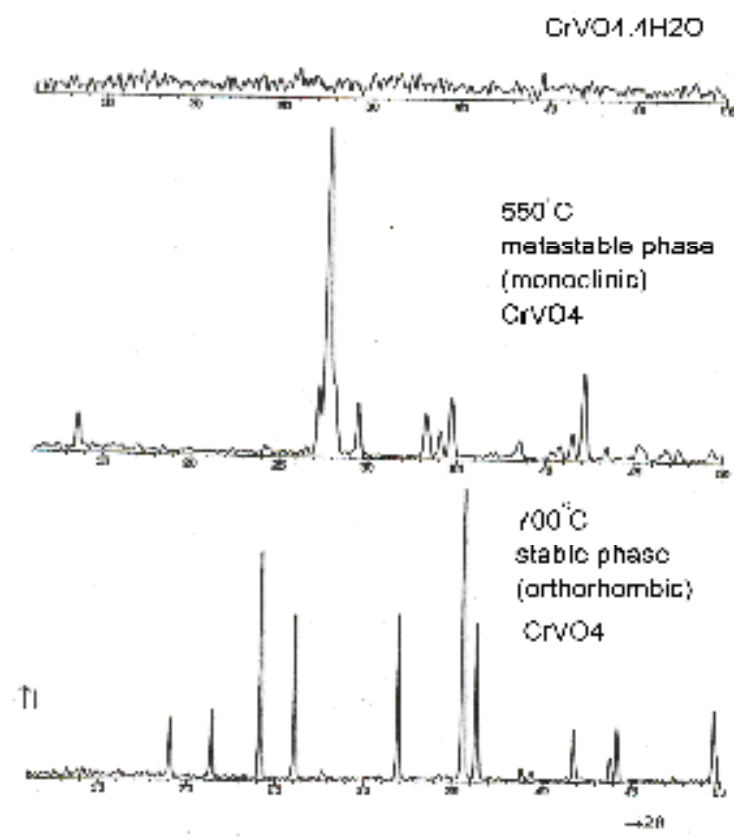

Figure 4. Powder X-ray diffraction of $\mathrm{CrVO}_{4}$ prepared by a soft chemistry technique and annealed at different temperatures (Touboul and Melghit, 1995).
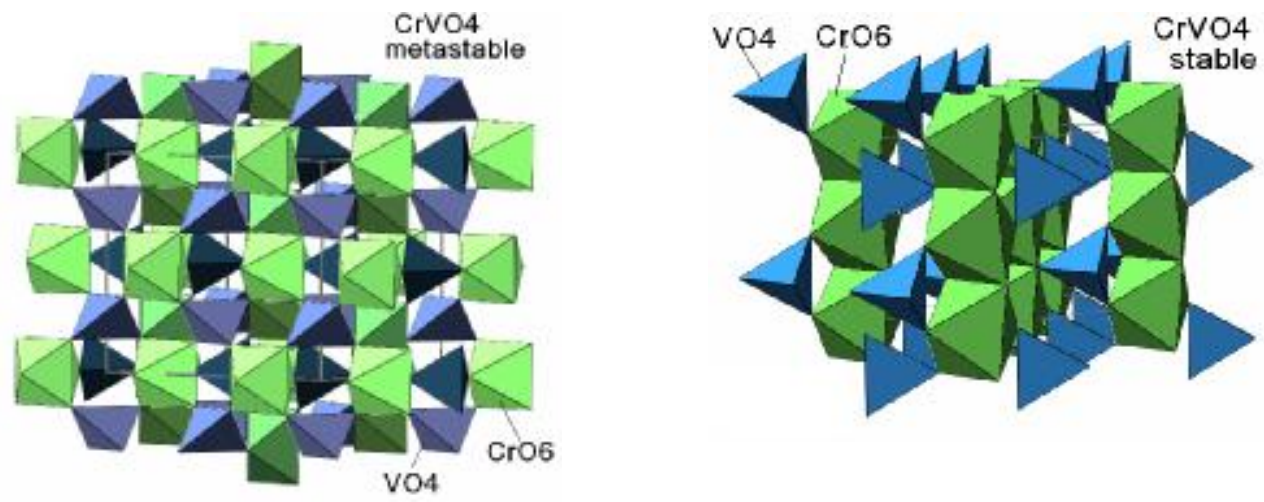

Figure 5. Polyhedral crystal representation of $\mathrm{CrVO}_{4}$ metastable (monoclinic) and $\mathrm{CrVO}_{4}$ stable (orthorhombic).

Similar to the chromium vanadate system a new metastable phase was also found on the indium vanadate system (Touboul et al, 1995; Touboul et al, 1994).

Also recently a new zinc pyrovanadate $\mathrm{Zn}_{3} \mathrm{~V}_{2} \mathrm{O}_{7}(\mathrm{OH})_{2} \cdot 2 \mathrm{H}_{2} \mathrm{O}$ was prepared at lower temperature using soft chemistry. It shows interesting open crystal structure Figure 6 that can find potential application (Zavalij et al, 1997; Melghit et al, 1999; Hoyos et al, 2005, Melghit et al, 2007). 


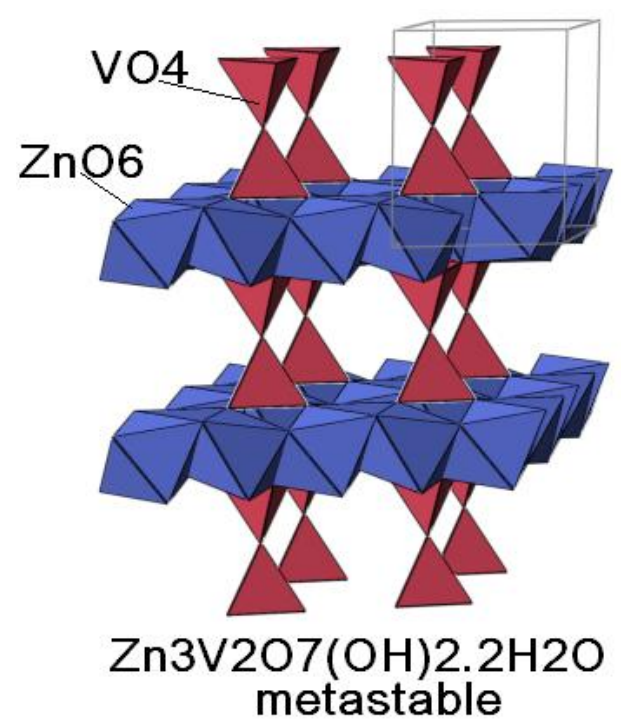

Figure 6. Polyhedral crystal representation of metastable $\mathrm{Zn}_{3} \mathrm{~V}_{2} \mathrm{O}_{7}(\mathrm{OH})_{2} .2 \mathrm{H}_{2} \mathrm{O}$

The question which can arise is why a solid sate technique cannot prepare the same metastable phases. In solid state reaction, the mixture must be heated at higher temperature to allow the diffusion between atoms; otherwise the reaction will not take place. The high temperature used exceeds in general the thermal stability of the metastable phase. Solid state reaction aims to prepare a stable phase, obtained at higher temperature, which possesses a lower free energy. The metastable phase is not the phase which possesses the lowest free energy in view of thermodynamic (Figlarz, 1994) however it is obtained mainly for kinetic reason. In each chemical reaction there are two parameters that affect the formation of product: kinetic and thermodynamic parameters. The metastable phase is not favorable in term of thermodynamics because its free energy is higher than the free energy of the stable phase but kinetically it is more favorable, it has lower activation energy. Thus, higher rate compared to the stable phase that allows this phase to appear but with limited range of thermal stability. It will transform to the stable phase if it is heated at higher temperature. In the previous example chromium orthovanadate is initially obtained from the solution as an amorphous phase Figure 4 . When this precipitate is heated at $500^{\circ} \mathrm{C}$ a new metastable phase is formed ( $\mathrm{CrVO}_{4}$ monoclinic). This phase is not the stable phase in the chromium vanadate system; the stable phase is orthorhombic $\mathrm{CrVO}_{4}$, but kinetically it is more favorable at that temperature $500^{\circ} \mathrm{C}$. If now the temperature is higher, $700^{\circ} \mathrm{C}$, the stable phase becomes favorable by both kinetic and thermodynamic; it will form and remain stable because it has the lowest free energy.

\subsection{Preparation of nanosize materials}

The other important point of soft chemistry that makes it attractive to the scientific community is its capability for preparing nanosize materials. Nanosize materials show higher surface area, more reactivity and interesting physical properties compared to the usual bulk materials. Nanotechnology is currently gaining interest from chemists, physists and biologists for its promising future. Because solid sate reaction uses higher temperature, the particles obtained are bigger and out off the nanosize range. The effect of temperature on particle size is known as can be seen from the following example: indium orthovanadate $\mathrm{InVO}_{4}$ can be obtained either from heating the metastable phase monoclinic at $600^{\circ} \mathrm{C}$ or by stirring the precursor obtained at room temperature for 6 hours (Melghit, 1994). The two materials have the same chemical composition and the same crystalline structure deduced from the x-ray diffraction spectra. Figure 7. The phase obtained at room 
temperature clearly shows very fine particles Figure 8 and broader X-ray diffraction peaks. In contrast the phase obtained by heating at $600^{\circ} \mathrm{C}$ shows bigger particles and sharper X-ray diffraction peaks.

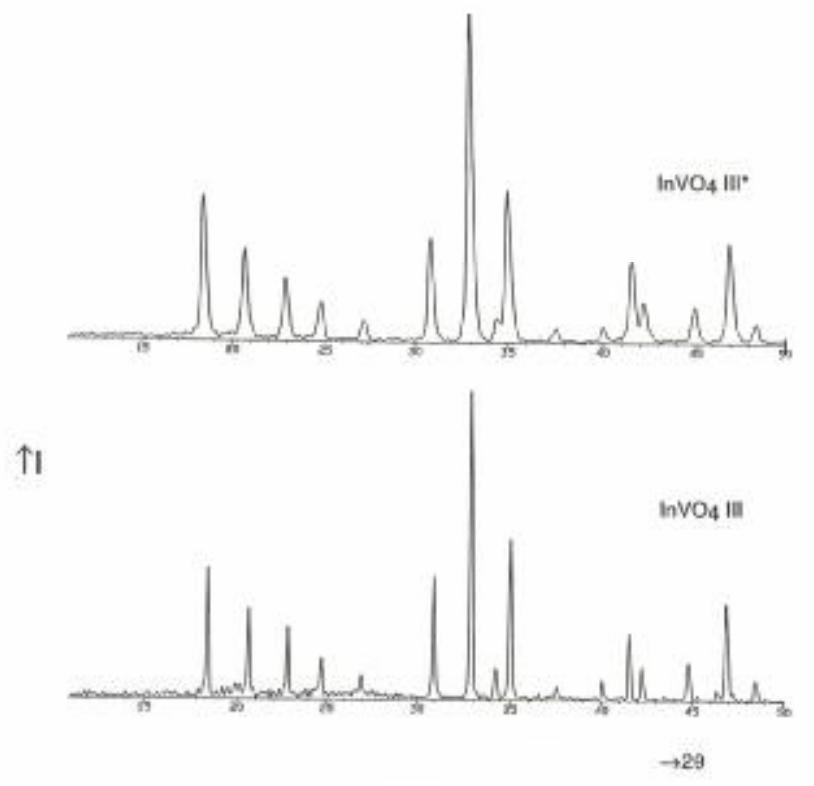

Figure 7. Powder X-ray diffraction of $\mathrm{InVO}_{4}$ III (prepared by heating a precursor at $600^{\circ} \mathrm{C}$ ) and $\mathrm{InVO}_{4} \mathrm{III}^{*}$ (obtained at room temperature).

As the temperature of preparation is lowered the particles obtained are smaller. Other example, such as spherical nanosize tin oxide, $\mathrm{SnO}_{2} \cdot \mathrm{xH}_{2} \mathrm{O}$, Figure 9 which can be obtained at room temperature using a simple soft chemistry technique starting from tin dichloride stirred in distilled water for several hours (K. Melghit, unpublished data).

\subsection{Some comment techniques used in the soft chemistry preparation}

\subsubsection{Sol-gel method}

A solution of molecular precursors is progressively transformed into an oxide network via inorganic polymerization reactions. Most precursors are metal alkoxides $\mathrm{M}(\mathrm{OR})_{\mathrm{z}}$ where $\mathrm{R}$ is an alkyl radical $\left(\mathrm{R}=\mathrm{CH}_{3}{ }_{3}\right.$, $\mathrm{C}_{2} \mathrm{H}^{*}{ }_{5}, \ldots$ ) (Bradley, 1978)

We can have hydrolysis with $\mathrm{H}_{2} \mathrm{O}$ :

$\mathrm{M}(\mathrm{OR})_{\mathrm{z}}+\mathrm{xHOH} \rightarrow \quad \mathrm{M}(\mathrm{OR})_{\mathrm{z}-\mathrm{x}}(\mathrm{OH})_{\mathrm{x}}+\quad \mathrm{x} \mathrm{ROH}$

Or condensation with a metal $\mathrm{M}^{\prime} \mathrm{OH}$

$\mathrm{M}(\mathrm{OR})_{\mathrm{z}}+\quad \mathrm{x} \mathrm{M}^{\prime} \mathrm{OH} \rightarrow \quad \mathrm{M}(\mathrm{OR})_{\mathrm{z}-\mathrm{x}}\left(\mathrm{OM}^{\prime}\right)_{\mathrm{x}}+\quad \mathrm{x} \mathrm{ROH}$

If $\mathrm{M}^{\prime}=$ organic or inorganic ligand, a complexation takes place 


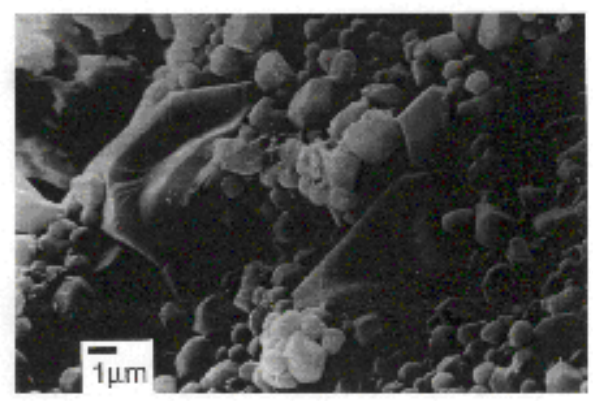

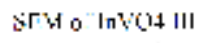

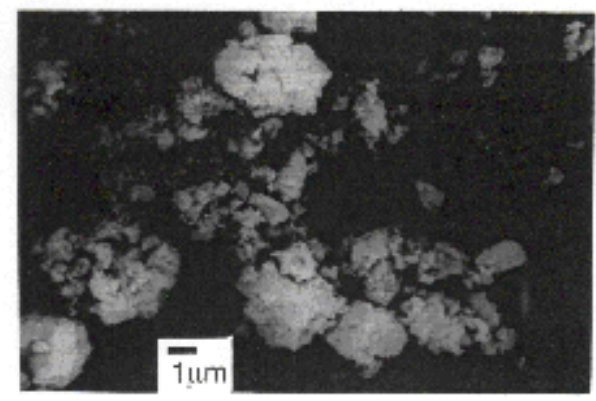

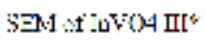

Figure 8. Scanning Electron Microscope (SEM) of $\mathrm{InVO}_{4}$ III prepared by heating a precursor at $600^{\circ} \mathrm{C}$ and $\mathrm{InVO}_{4} \mathrm{III}^{*}$ obtained at room temperature.

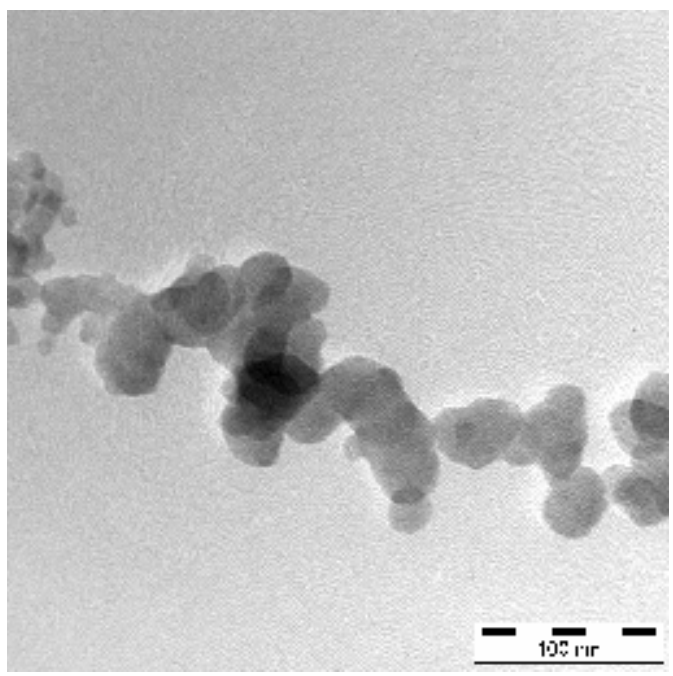

Figure 9. TEM micrograph of $\mathrm{SnO}_{2} \cdot \mathrm{xH}_{2} \mathrm{O}$ particles. 


\section{KHALED MELGHIT}

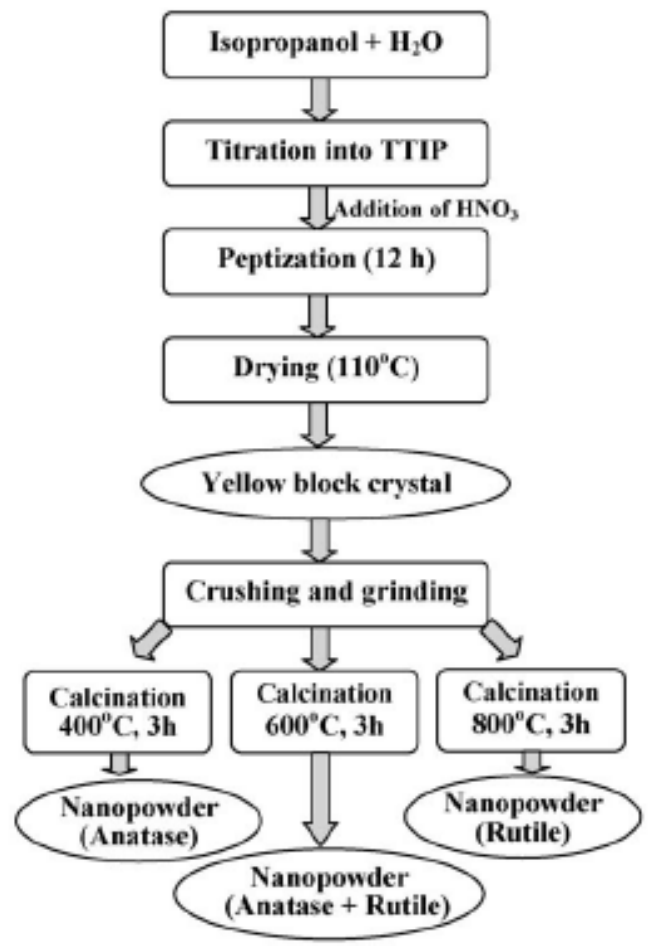

Figure 10. Flow chart showing preparation of nano- $\mathrm{TiO}_{2}$ powders through a sol-gel process (Qiu et al, 2006).

The metal alkoxides continue its hydrolysis until the protonated ROH ligand is finally removed. It is reported (Livage, 1994) that the chemical reactivity of metal alkoxides toward hydrolysis and condensation mainly depends on the positive charge of the metal atom $\mathrm{M}$ and its ability to increase its coordination number $\mathrm{N}$. As the general rule, as the electronegativity of metal atoms decreases and their size increases when going down the periodic table the corresponding alkoxides become progressively more reactive toward hydrolysis and condensation. Silicon alkoxides are rather stable while alkoxides of electropositive metals must be handled with care under a dry atmosphere.

This method is increasingly being used and many examples of such technique exists in the literature. Some examples are given below

a) Preparation of anatase nanotubes as support for platinum nanocrystals (Eder et al, 2006): The carbon nanotubes were coated by a sol-gel template method, followed by a hydrothermal treatment. The gel is formed from titanium alkoxide (such as titanium isopropoxide) which was dissolved in ethanol and slowly dropped into carbon nanotubes suspension. The titanium precursor hydrolyses with water to form hydroxyl group that will further condense in the process to build up a gel type Ti-O-Ti network. Heating the sample at $500^{\circ} \mathrm{C}$ will removed the carbonaceous template.

b) Preparation of nanocrystalline titanium dioxide (Qiu et al, 2006): The method is shown in the flow chart of Figure 10.

This method uses an organic sol-gel technique that leads to preparation of nanosize anatase $\mathrm{TiO}_{2}$. An inorganic sol-gel method was recently used and the same product was obtained (Melghit et al, in press). The method consists of dissolving titanium trichloride in water, after that hydrogen peroxide was added and the 


\section{SOFT CHEMISTRY ROUTES TO NEW NANOSIZE MATERIALS}

mixture was stirred for several hours, then ammonium hydroxide was added. An amorphous yellow gel was obtained which crystallized to pure anatase after heating at $300^{\circ} \mathrm{C}$ Figure 1.

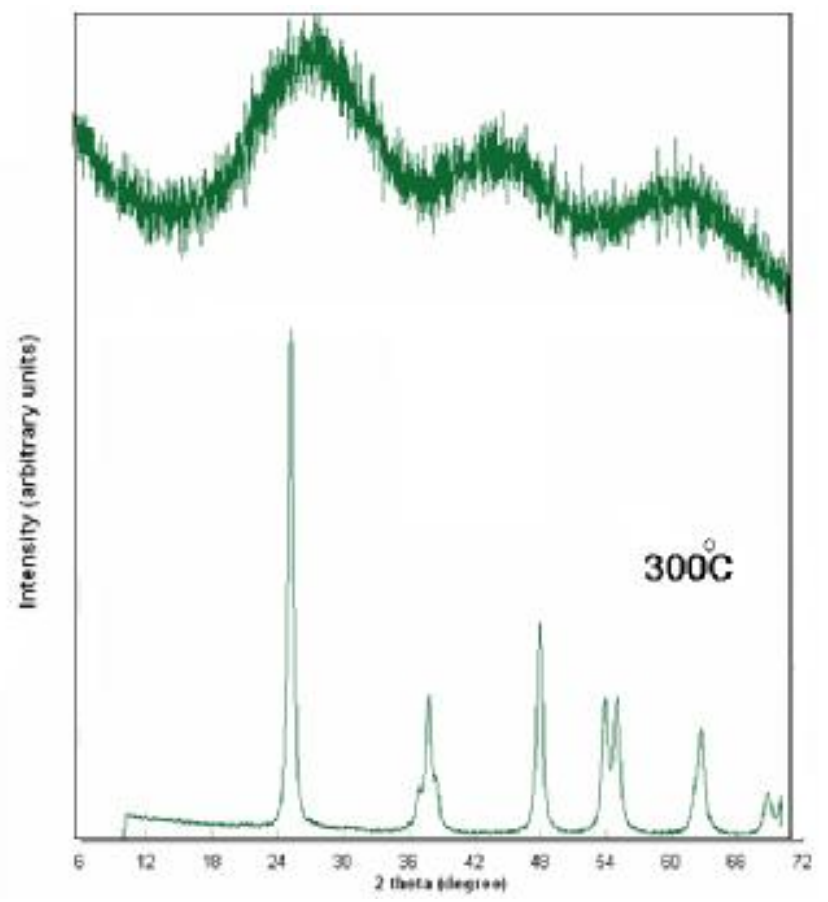

Figure 11. Powder X-Ray diffraction of $\mathrm{TiO}_{2}$ anatase obtained by using aqueous sol-gel method (Melghit et al, in press).

c) Preparation of $\mathrm{In}_{2} \mathrm{O}_{3}$ nanorods (Cheng et al, 2006): indium chloride was added to polyethylene octyl phenyl ether and stirred and then the ammonia was added. The gel obtained was heated at $500^{\circ} \mathrm{C}$ to obtain $\mathrm{In}_{2} \mathrm{O}_{3}$ nanorods.

d) Preparation of $\mathrm{TiO}_{2}$ nanorods rutile (Melghit and Al-Rabaniah, 2006): inorganic sol-gel method was also used for preparing nanorods $\mathrm{TiO}_{2}$. $\mathrm{TiCl}_{3}$ solution was stirred in water for several hours after that ammonium hydroxide was added. The gel obtained is formed from crystalline pure nanorods rutile $\mathrm{TiO}_{2}$ Figure 12.

\subsubsection{Precipitation method}

The precipitation method is widely used in recent years for preparing many new materials. In general, the product is obtained from a solution medium. The precipitate depends mainly on the experimental conditions like the $\mathrm{pH}$, temperature and reaction time. The starting materials should be soluble in the solution and should be able to precipitate to form the new product. By changing the experimental conditions $(\mathrm{pH}$, temperature, and reaction time) it is possible to find the optimum experimental parameters where a new phase can precipitate. For example, in preparing mixed oxide like zinc pyrovanadate $\mathrm{Zn}_{3} \mathrm{~V}_{2} \mathrm{O}_{7}(\mathrm{OH})_{2} \cdot 2 \mathrm{H}_{2} \mathrm{O}$ (Melghit et al, 1999); two solutions should be prepared. The first solution will contain vanadium ions and the second solution will contain zinc ions. When the two solutions are mixed, a clear solution is formed. However by increasing the $\mathrm{pH}$, using ammonium hydroxide, and heating to boiling temperature, a precipitate of zinc vanadium oxides was obtained. In other preparations, a precipitate is obtained without $\mathrm{pH}$ control. An example of such preparation is iron orthovanadate $\mathrm{FeVO}_{4}$ (Melghit and Al-Mungi). When the two solutions which contains iron ions and vanadium 


\section{KHALED MELGHIT}

ions, are mixed a precipitate is obtained immediately without $\mathrm{pH}$ control. Sometime, in soft chemistry preparation, material formed presents a different composition compared to the initial composition of reactants; this is different to solid state reaction where the product composition usually has the composition of initial reactants.

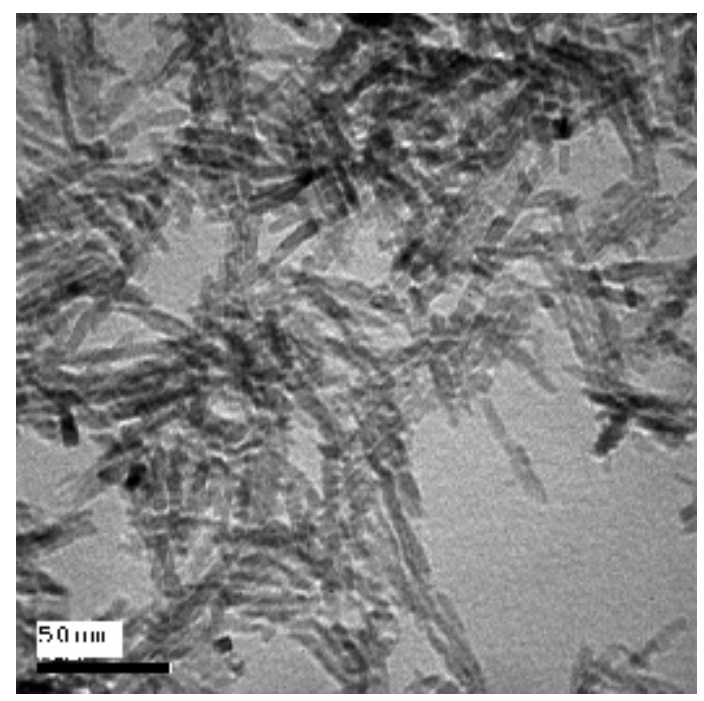

Figure 12. TEM Micrograph of nanorods $\mathrm{TiO}_{2}$ rutile (Melghit and Al-Rabaniah, 2006).

\subsubsection{Hydrothermal method}

The term hydrothermal came from the earth sciences, where it implies a regime of high temperatures and water pressure. The technique uses a high temperature and pressure apparatus called autoclaves or bombs. Hydrothermal synthesis usually involves water heated at higher boiling temperature $\left(>100^{\circ} \mathrm{C}\right)$ with a higher pressure ( $>$ few atmospheres) compared to the normal atmosphere. Many chemical hydrothermal experiments have led to many metastable phases that have open structure and interesting application. Some time a templating ion was used in order to modify the product. Also the $\mathrm{pH}$ was found to be important and affect the final product. For example if $\mathrm{Na}_{2} \mathrm{WO}_{4}$ is acidified with $\mathrm{HCl}$ and is heated in an aqueous environment at $150^{\circ} \mathrm{C}$, both a one dimension and three dimension tunnel structure are formed depending on the initial $\mathrm{pH}$ of the reaction medium (Whittingham, 1994). Beside that the technique was also used for preparing fine oxide powders (Somiya et al, 2000).

\subsubsection{Intercalation and deintercalation}

Usually these types of reaction take place in the lamellar compounds. For example $\mathrm{Li}_{2} \mathrm{FeS}_{2}(\mathrm{Ouvrard}$ et al, 1994) has hexagonal close packing layers of sulfur atoms with iron in tetrahedral sites. Lithium atoms are found in equal proportions in octahedral sites between the S-Fe-S layers and in tetrahedral sites inside these layers. Lithium presents a high mobility it can be intercalated or deintercalated from the host chemical or electrochemically. It can be removed from the host by stirring the $\mathrm{Li}_{2} \mathrm{FeS}_{2}$ powder suspension in an iodine/acetonitrile solution or electrochemically by recharging a lithium battery. Another similar example is deintercalated of lithium from $\mathrm{LiMn}_{2} \mathrm{O}_{4}$ (Coowar et al, 1994).

From these examples, by using soft conditions, soft chemistry preparation offer many advantages over classical method such as preparation of new interesting metastable phase. It leads also to the same material prepared by the solid state reaction but at lower temperature. This will save energy and lower the production 
cost. In addition, the product obtained shows a higher level of purity and nanosize particles that lead to high surface area and hence higher reactivity. Although the preparation using soft chemistry appears to be easy, it is not straightforward because starting reactants must be soluble in the solution which is not always the case. Besides, the knowledge of behavior of reactant species in the solution with $\mathrm{pH}$ will be advantageous. For example in precipitation reaction, if two elements have to be obtained in the final product, it is important to find a common $\mathrm{pH}$ value where the two metals can precipitate in the same time. Also it is important to give attention during experiment to other parameters such as temperature, stirring time and heating. Such experiments are very sensitive to experimental conditions and a missed detail, even small, can be the cause of not getting the same product. For example a longer stirring time for few hours can instead affect the product to become crystallized which is obtained initially as amorphous phase (Melghit, 1994). As its name indicates, the soft chemistry is soft and sensitive to experimental conditions and therefore care should be taken to record every experimental step.

\section{Conclusion}

Although solid state reaction remains used in the laboratory until today, it presents less advantages in advancement of recent applications. The industries, which are under technological challenge, are more demanding for new materials with specific characteristic and better physical properties. Often, these new materials are metastable phases that can be prepared only by soft chemistry techniques. The nanotechnology field takes more importance with time and becomes research area for many laboratories over the world. This is absolutely the domain of soft chemistry. By using high temperature that leads to bigger particles, solid state reaction cannot compete with soft chemistry in such area. In the recent years, soft chemistry or chimie douce was given more interest by the scientific community, indeed a sol-gel research journal was created in 1995, and several conferences on the subject took place. This indicates the role of such technique in chemistry of advanced inorganic materials.

\section{References}

BRADLEY, D.C., MEHROTRA, R.C., GAUR, D.P. 1978. metal Alkoxides, Academic Press, London.

CHANG, Y.S., CHANG, Y.H., CHEN, I.G., CHEN, G.J., CHAI, Y.L., FANG, T.H., Wu, S. 2004. Synthesis, formation and characterization of $\mathrm{ZnTiO}_{3}$ ceramics. Ceram. International, 30: 2183-2189.

CHEN, X.M., WANG, T., LI, J. 2004. Dielectric characteristics and their field dependence of (Ba, Ca) $\mathrm{TiO}_{3}$ ceramics. Mater. Sci. Eng. B, 113: 117-120.

CHENG, Z-X., DONG, X-B., PAN, Q-Y., ZHANG, J-C., DONG, X-W. 2006. Preparation and characterization of $\mathrm{In}_{2} \mathrm{O}_{3}$ nanorods. Mater. Lett., 60: 3137-3140.

COOWAR, F., TARASCON, J.M., MCKINNON, W.R., GUYOMARD, D. 1994. Lithium deintercalation in the spinel $\mathrm{LiMn}_{2} \mathrm{O}_{4}$. Mater. Sci. Forum.152-153: 213-216.

ELDER, D., MOTTA, M.S., KINLOCH, I.A., WINDLE, A.H. 2006. Anatase nanotubes as support for platinu nanocrystals Physica E. in press.

FIGLARZ, M. 1994. Soft Chemistry: Thermodynamic and structural aspects. Mater. Sci. Forum. 152-153: 5568.

HEIRAS, J., PICHARdo, E., MAHMOUd, A., LOPEZ, T., PEREZ-SAlAS, R., SIQUEIROS, J.M., BLANCO, M., CASTEllanOS, M. 2002. Thermochromism in (Ba, Sr)-Mn oxides, J. Phys. Chem. Solids. 63: 591-595.

HOYOS, D., PAILLAUD, J.-L., IMON-MASSERON, A., GUTH, J.-L. 2005. Synthesis, characterization and structure determination of a three-dimensional hydrated potassium zinc divanadate: $\mathrm{K}\left[\mathrm{Zn}_{2.5} \mathrm{~V}\right.$ $\left.{ }_{2} \mathrm{O}_{7}(\mathrm{OH})_{2}\right] \cdot \mathrm{H}_{2} \mathrm{O}$. Solid State Sci., 7(5): 616-621.

LIVAGE, J. 1977. Le Monde, October $26^{\text {th }}$, France.

LIVAGE, J. 2001. Chimie douce: from shake-and-bake processing to wet chemistry New J. Chem., 25:1. 


\section{KHALED MELGHIT}

LIVAGE, J. 1994. The Sol-Gel route to advanced materials. Mater. Sci. Forum 152-153: 43-54.

MELGHIT, K., AL-BELUSHI, A.K., AL-AMRI, I. 2007. Short reaction time preparation of zinc pyrovanadate at normal pressure. Ceram. International, 33: 285-288.

MELGHIT, K. 1994. Thesis. Universite of picardie France.

MELGHIT, K., AL-MUNGI, A.S. 2006. New form of iron orthovanadate $\mathrm{FeVO}_{4} .1 .5 \mathrm{H}_{2} \mathrm{O}$ prepared at normal pressure and low temperature. Mater. Sci. Eng. B. 136: 177-181

MELGHIT, K., AL-RABANIAH, S.S. 2006. Photodegradation of Congo red under sunlight catalysed by nanorod rutile $\mathrm{TiO}_{2}$. Journal of Photochem. and Photobiol. A: Chem. 184: 331-334.

MELGHIT, K., BELLOUI, B., YAHAYA, A.H. 1999. Room temperature preparation of Zinc Pyrovanadate $\mathrm{Zn}_{3}(\mathrm{OH})_{2} \mathrm{~V}_{2} \mathrm{O}_{7} .2 \mathrm{H}_{2} \mathrm{O}$. J. Mater. Chem., 9(7): 1543-1545.

MELGHIT, K., RABANIAH, S., AL-AMERI, I. 2006. Low temperature preparation and characterization of nanospherical anatase $\mathrm{TiO}_{2}$ and its photocatalytic activity on Congo red degradation under sunlight. Ceram. international. Accepted.

OUVRARD, G., PROUZET, E., BREC, R., ROUXEL, J. 1994. Some chalcogenides syntheses via soft chemistry. Mater. Sci. Forum.152-153:143-148.

POEPPELMEIER, K.R., TOMCZAK, D.C. 1994. Soft Chemistry routes to oxides catalysts, Mater. Sci. Forum. 152-153: 163-168.

QIU, S., KALITA, S.J. 2006. Synthesis, processing and characteriasation of nanocrystalline titanium dioxide. Mater. Sci. Eng. A. 435-436: 327-332.

ROUXEL, J. 1988. Chemical reactivity of low-dimensional solids., Chemica Scripta, 61: 33.

SHISHIDO, T., SONG, Z., KADOWAKI, E., WANG, Y., TAKEHIRA, K. 2003. Vapor-phase oxidation of 3picoline to nicotinic acid over $\mathrm{Cr}_{1-\mathrm{x}} \mathrm{Al}_{\mathrm{x}} \mathrm{VO}_{4}$ catalysts Appl. Catal. A: General 239: 287-296.

SOMIYA, S., ROY, R. 2000. Hydrothermal Synthesis of fine oxide powders Bull. Mater. Sci., 23: 453-460.

SONG, Z., MATSUSHITA, T., SHISHIDO, T., TAKEHIRA, K. 2002. Crystalline $\mathrm{CrV}_{0.95} \mathrm{P}_{0.05} \mathrm{O}_{4}$ catalyst for vapor-phase oxidation of picolines Chem. Communication, 12: 1306-1307.

SONG, Z., MATSUSHITA, T., SHISHIDO, T., TAKEHIRA, K. 2003.Crystalline $\mathrm{CrV}_{1-\mathrm{x}} \mathrm{P}_{\mathrm{x}} \mathrm{O}_{4}$ catalysts for the vapor-phase oxidation of 3-picoline. J. Catal., 218: 32-41.

TOUBOUL, M., MELGHIT, K., BENARD, P. 1994. Synthesis by chimie douce and characterisation of indium vanadates. Eur. J. Solid State Inorg. Chem., 31: 151-161.

TOUBOUL, M., MELGHIT, K. 1995. Synthesis by chimie douce and properties of chromium (III) vanadates (V). J. Mater. Chem., 5(1): 147-150.

TOUBOUL, M., MELGHIT, K., BENARD, P., LOUER, D. 1995 Crystal structure of a metastable form of indium orthovanadate $\mathrm{InV}_{4}$-I.. J. Solid State. Chem., 118: 9398.

VARMA, S., WANI, B.N., SATHYAMOORTHY, A., GUPTA, N.M. 2004. On the role of lattice distortion in the catalytic properties of substituted orthovanadates $\mathrm{La}_{1-\mathrm{x}} \mathrm{Fe}_{\mathrm{x}} \mathrm{VO}_{4}$. J. Phys. Chem. Solids 65: 1291-1296.

WHITTINGHAM, M.S., LI, J., GUO, J.D., ZAVALIJ, P. 1994. Hydrothermal synthesis of new oxide materials using the tetrametyhyl ammonium. Mater. Sci. Forum. 152-153: 99-108.

WEISS, P.B. 1973. Zeolites-New Horizons in Catalysis., Chemtech, p. 498.

ZHAOXIA, S., KADOWAKI, E., SHISHIDO, T., WANG, Y., TAKEHIRA, K. 2001. 3-picoline oxidation over monoclinic orthovanadate $\mathrm{Cr}_{0.5} \mathrm{Al}_{0.5} \mathrm{VO}_{4}$ catalysts. Chem. Letters 8: 754-755.

ZAVALIJ, P.Y., ZHANG, F., WHITTINGHAM, M.S. 1997. A new zinc pyrovanadate, $\mathrm{Zn}_{3}(\mathrm{OH})_{2} \mathrm{~V}_{2} \mathrm{O}_{7} .2 \mathrm{H}_{2} \mathrm{O}_{\text {, }}$ from X-ray powder data. Acta Crystallogr. Sect. C: Cryst. Struct. Communications 53:1738-1739.

Received 6 December 2006

Accepted 24 June 2007 